\title{
A reconstruction of global agricultural areas and land cover for the last millennium
}

\author{
J. Pongratz, ${ }^{1,2}$ C. Reick, ${ }^{1}$ T. Raddatz, ${ }^{1}$ and M. Claussen ${ }^{1,3}$ \\ Received 26 November 2007; revised 1 April 2008; accepted 8 May 2008; published 21 August 2008.
}

[1] Humans have substantially modified the Earth's land cover, especially by transforming natural ecosystems to agricultural areas. In preindustrial times, the expansion of agriculture was probably the dominant process by which humankind altered the Earth system, but little is known about its extent, timing, and spatial pattern. This study presents an approach to reconstruct spatially explicit changes in global agricultural areas (cropland and pasture) and the resulting changes in land cover over the last millennium. The reconstruction is based on published maps of agricultural areas for the last three centuries. For earlier times, a country-based method is developed that uses population data as a proxy for agricultural activity. With this approach, the extent of cropland and pasture is consistently estimated since AD 800. The resulting reconstruction of agricultural areas is combined with a map of potential vegetation to estimate the resulting historical changes in land cover. Uncertainties associated with this approach, in particular owing to technological progress in agriculture and uncertainties in population estimates, are quantified. About 5 million $\mathrm{km}^{2}$ of natural vegetation are found to be transformed to agriculture between $\mathrm{AD} 800$ and 1700, slightly more to cropland (mainly at the expense of forested area) than to pasture (mainly at the expense of natural grasslands). Historical events such as the Black Death in Europe led to considerable dynamics in land cover change on a regional scale. The reconstruction can be used with global climate and ecosystem models to assess the impact of human activities on the Earth system in preindustrial times.

Citation: Pongratz, J., C. Reick, T. Raddatz, and M. Claussen (2008), A reconstruction of global agricultural areas and land cover for the last millennium, Global Biogeochem. Cycles, 22, GB3018, doi:10.1029/2007GB003153.

\section{Introduction}

[2] One of the most striking impacts of humankind on its environment is the transformation of natural ecosystems to managed areas. At present, $30-50 \%$ of the Earth's land cover have been substantially modified by human land use, primarily by the expansion of agriculture [Vitousek et al., 1997]. By 2003, about 15 million $\mathrm{km}^{2}$ of cropland and 34 million $\mathrm{km}^{2}$ of pasture have replaced natural land cover (Food and Agricultural Organization (FAO), FAOSTAT: Land use, FAO Statistics Division, available at http://faostat.fao.org), providing much of the ecosystem goods and services humanity has become dependent on. Such large-scale modifications of the land surface can have important consequences for the Earth system, most notably through their impact on ecological functioning, and the biogeophysical and biogeochemical interactions with the atmo-

\footnotetext{
${ }^{1}$ Max Planck Institute for Meteorology, Hamburg, Germany.

${ }^{2}$ International Max Planck Research School on Earth System Modelling, Hamburg, Germany.

${ }^{3}$ Meteorological Institute, University of Hamburg, Hamburg, Germany.

Copyright 2008 by the American Geophysical Union. 0886-6236/08/2007GB003153
}

sphere. Significant changes in structure and functioning of ecosystems and a loss of biodiversity have already been attributed to human interference [United Nations Environment Program (UNEP), 1995; Haberl et al., 2007]. Energy balance and hydrological cycle are significantly affected by present-day land use activity [Betts, 2001; Davin et al., 2007], and global carbon and nitrogen cycles have been altered severely [Galloway et al., 1995; Denman et al., 2007]. For example, about $35 \%$ of anthropogenic $\mathrm{CO}_{2}$ emissions during the last 150 years resulted directly from land use [Houghton, 2003], making it one of the key agents of anthropogenic climate change. Recognition of land use as a possible way to mitigate climate change and the increasing concern of the scientific community about the availability of natural resources has further brought the consequences of human-induced land cover change to public awareness [Millennium Ecosystem Assessment, 2005; Barker et al., 2007].

[3] Given the growing evidence of the impact anthropogenic land cover change exerts on the Earth system, it is not surprising that today much effort is put into quantifying these changes. In recent years, remote sensing offers a valuable tool for monitoring land cover change [Townshend et al., 1991; Brown de Colstoun et al., 2006]. Historical data of agricultural activity allow rather solid estimates for the 
last 300 years [Ramankutty and Foley, 1999; Klein Goldewijk, 2001]. By contrast, quantifications of global land cover change prior to AD 1700 are scarce, although it is well known that humans have actively managed and transformed the world's landscapes already for millennia [Grigg, 1974]. It is also recognized that these preindustrial land cover changes may have significantly contributed to the variability of atmospheric composition observed from ice core records [DeFries et al., 1999; Ruddiman, 2007]. Yet, the strength of human impact is still highly controversial [Joos et al., 2004]. Much of the dispute is centered around the lack of knowledge concerning extent, timing, and spatial pattern of historical land cover change. Those studies that have so far accounted for anthropogenic land cover change in preindustrial times in global and regional Earth system studies used the simplification to either keep land cover fixed prior to the 18th century [e.g., Stendel et al., 2006; Tett et al., 2007] or to linearly interpolate between potential vegetation in AD 1000 and the state of land cover of AD 1700 [e.g., Brovkin et al., 1999; Goosse et al., 2006]. Both approaches, however, entirely disregard any detail of human history.

[4] In this study, we present the first detailed reconstruction of global agricultural areas (cropland and pasture) and the resulting changes in land cover over the last millennium. Special emphasis is placed on the preindustrial period, as it has not been subject of consistent analysis before. In the time period between AD 800 and the early 18th century, the world's population tripled [McEvedy and Jones, 1978]. As more people required more food and commodities from agriculture and natural resources, this period must have been associated with agricultural expansion at an unprecedented pace [Grigg, 1974; Richards, 1990]. As reliable data on historical agricultural areas is sparse, we develop a simple method for its reconstruction based on population estimates. Agriculture is inherently linked to population [Vasey, 1992], which allows us to use country-based estimates of historical population as proxy for agricultural areas. With this method, the cropland and pasture maps of Ramankutty and Foley [1999] and Foley et al. [2003] at 0.5 degree resolution for the last 300 years are extended back into the past to give consistent estimates of cropland and pasture since $\mathrm{AD} 800$ on a geographically explicit basis. This "millennium reconstruction" of agricultural areas is combined with a map of potential vegetation to also estimate historical changes in land cover.

[5] The reconstruction of agricultural areas is restricted to cropland and pasture. For cropland, the definition of "arable and permanent crops" from the Food and Agricultural Organization (FAO) is adopted, which includes land under temporary and permanent crops, temporary meadows for mowing or pasture, land under market and kitchen gardens, and land lying temporarily fallow. The abandoned land resulting from shifting cultivation is not included. For pasture, the FAO category "permanent pasture" is used. It includes all land used permanently for herbaceous forage crops, either cultivated or growing wild.

[6] The following sections describe in detail the different steps taken to reconstruct global agricultural areas and land cover for the last millennium. These steps are summarized in Figure 1.

\section{Step 1: Adaptation of Agricultural Data Since AD 1700}

[7] Recent years have seen an increasing interest in developing data sets of agricultural areas covering at least the entire industrial period. Most noteworthy are the achievements of the Center for Sustainability and the Global Environment (SAGE), University of Wisconsin [Ramankutty and Foley, 1999; Foley et al., 2003] and the History Database of the Global Environment (HYDE), Netherlands Environmental Assessment Agency [Klein Goldewijk, 2001]. These are high-resolution maps of cropland and pasture for the last three centuries based on various contemporary and historical statistical inventories on agricultural land. Different spatial allocation algorithms were applied to provide geographically explicit maps, intended in the first place for the use in ecosystem, climate, and integrated models. In the following, we describe how we integrate these maps into a single consistent data set for cropland and pasture for $\mathrm{AD}$ 1700 to 1992 (step 1 of Figure 1). We thereby rely on the SAGE data where possible as its fractional character supplies additional subgrid information.

\subsection{Cropland}

[8] Ramankutty and Foley [1999] developed a simple algorithm to link present remote sensing data and historical cropland inventories. Inventory data was compiled on the level of today's political units (subnational data for some of the largest countries) and is based on data published by the Food and Agricultural Organization (FAOSTAT) for 1961-1992 and a variety of sources for earlier times, most notably estimates from Houghton and Hackler [1995] and Richards [1990]. We use their time series AD 1700 to 1992 of global croplands for the millennium reconstruction, but apply some revisions. First, we replace the West Africa region by the improved regional data set of Ramankutty [2004], which we extend to previous years using population trends [Klein Goldewijk, 2001]. We apply some further corrections of the cropland pattern in the 18th and 19th century for specific regions to better match historical evidence. They were necessary in order to provide suitable maps as starting point for the reconstruction of earlier centuries. In particular, the lack of subnational data in the Former Soviet Union (FSU) led to maintenance of the 1992 crop pattern and to significant crop area in Siberia in historical times. We redistribute total crop area using subnational population data derived from McEvedy and Jones [1978] and United Nations Statistics Division (Population density and urbanization, 2006, UN Department of Economic and Social Affairs, available at http://unstats.un.org/unsd/ demographic/sconcerns/densurb/). In a similar way, the crop pattern of Australia and New Zealand are adjusted to reflect the history of European immigration (for details, see Pongratz et al. [2008]). 


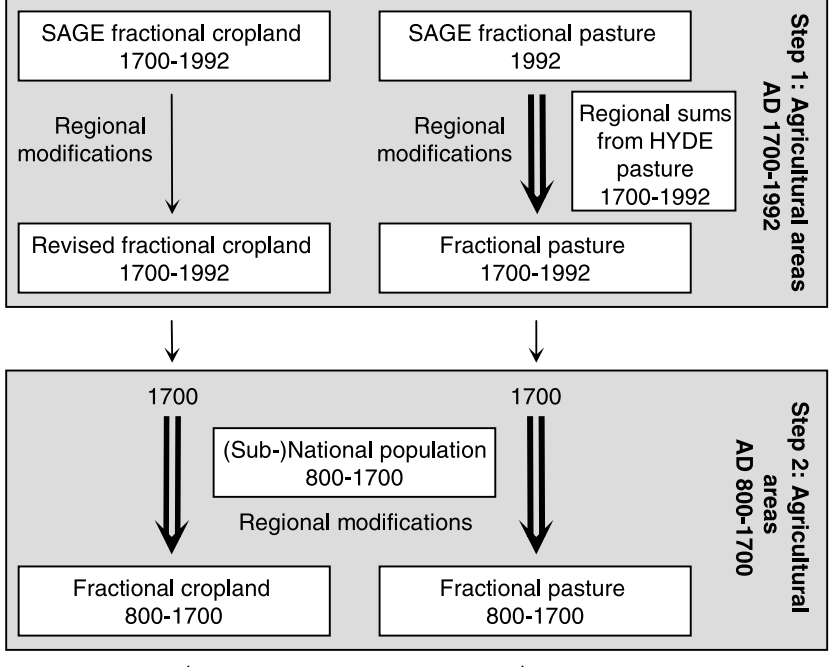

Reconstruction of agricultural areas 800-1992

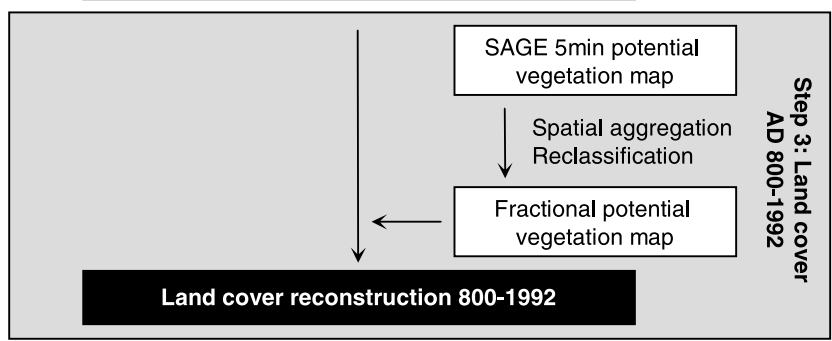

Figure 1. Scheme for reconstructing agricultural areas and land cover AD 800 to 1992. Double arrows indicate linear backscaling.

\subsection{Pasture}

[9] For global pastures, where SAGE provides only a single map for 1992, we extend this data to a time series AD 1700 to 1992. First, we calculate regional totals of pasture area for each year from the 1992 areas and rates of change from Klein Goldewijk [2001]. Calculations are performed on country level after 1960 and for the 10 regions defined by Houghton et al. [1983] prior to 1960 adapting the same regional breakdown as has been used for the temporal information of HYDE. For each year, the pasture totals are then distributed spatially within each country or region. While the method of Ramankutty and Foley [1999] to extend the 1992 map of cropland back into the past was to generally maintain the 1992 pattern of cropland throughout time (i.e., the grid cells within a country keep their cropland fractions in the same proportion relative to each other, while the total area changes with time), we chose a different method for pasture. The pasture area is thereby distributed around the existing cropland in a way that not the pattern of pasture, but of total agricultural area (cropland plus pasture) is maintained throughout time. The advantage of this method is that it allows to take into account the expansion of crop on pasture area that has been observed in the past [Grigg, 1974]. The modifications applied to the crop time series concerning Australasia are also applied to the pasture time series. The modifications concerning the FSU are unnecessary as the pasture areas here are connected to the extensive areas of traditional nomadic pastoralism of Kazakhstan and Mongolia [Kerven et al., 2006].

\section{Step 2: Reconstruction of Agricultural Areas AD 800 to 1700}

[10] Statistical databases built by international organizations and, more recently, remote sensing provide us with data and methods to consistently measure agricultural areas and land cover change of the last decades. Great efforts have been undertaken to extend this data back into the past; most notable with respect to its global coverage is the work by Houghton [1999], who compiled a multitude of regional studies related to historical land cover, and the data compilation by Richards [1990], which are basis also of the SAGE and HYDE studies. However, sources which address more than the local level become scarce when going back in time and rarely go beyond $\mathrm{AD}$ 1650. Thus, we search for a proxy for agricultural area for which historical data is more readily available on global scale.

[11] We therefore utilize in this study the fact that agriculture is inherently linked to population. Prior to the 19th century, technology played a minor role in resource extraction, and transportation was a limiting factor in preindustrial times for trading large quantities of agricultural input and output over long distances [Vasey, 1992]. Even if most societies had outgrown individual subsistence farming, autonomy for basic needs still had to be largely realized on a regional level [Allen, 2000]. It is therefore appropriate to assume that agriculture occurred where people had settled, and the amount of land under human use is likely well correlated to the number of people who had to be nourished. For this reason, we use population estimates as proxy for agricultural areas. Information on historical population numbers are much more readily available than on land cover; our main source of population data for $\mathrm{AD}$ $800-1700$ is the Atlas of World Population History by McEvedy and Jones [1978], with regional modifications for Central and South America based on the work of Clark [1967]. McEvedy and Jones provide totals for most of today's countries from $400 \mathrm{BC}$ to $\mathrm{AD} 1975$ based on a multitude of publications and support their estimates with short essays stressing among others the role of agriculture. Where only data for larger regions is provided, we break the historical numbers down to country level using the HYDE population density map of AD 1700, assuming that the national proportions within a region remain constant. For some regions, subnational data was used, especially for the FSU and Central and South America. In the latter region, national numbers are broken down to better represent the spatial heterogeneity between the high cultures, with a significantly higher population density, and other tribes in pre-Columbian times (for details, see Pongratz et al. [2008]).

[12] Population numbers are then translated for each country into estimates of crop and pasture area. In the absence of further information, it seems inappropriate to 

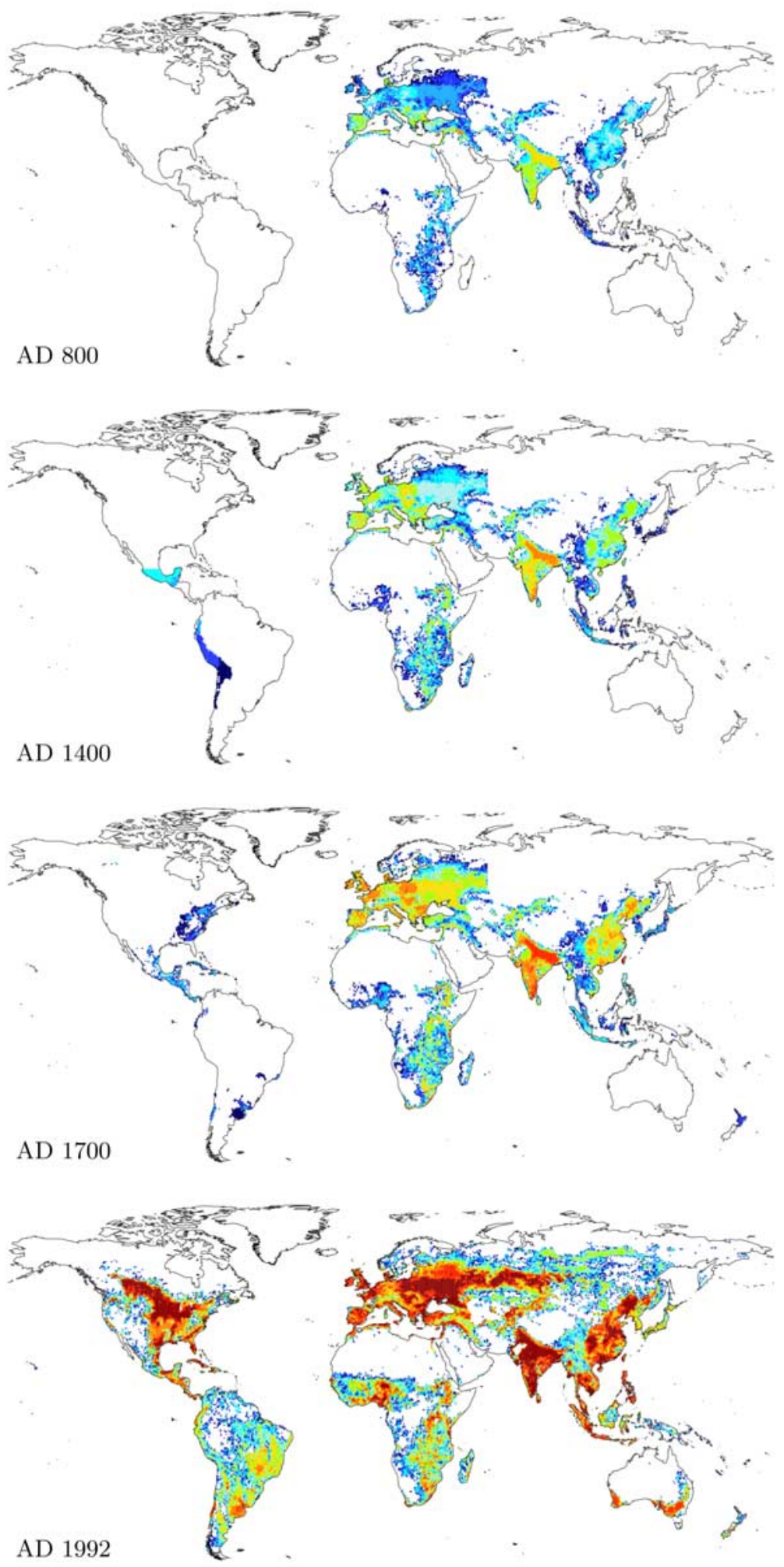

$\begin{array}{lllllllllll}0.0 & 1.6 & 2.5 & 4.0 & 6.3 & 10 & 16 & 25 & 40 & 63 & 100\end{array}$

Figure 2. Global historical cropland area. Units are percent of grid cell. Values smaller than $1 \%$ are colored white. Note the logarithmic scale. 

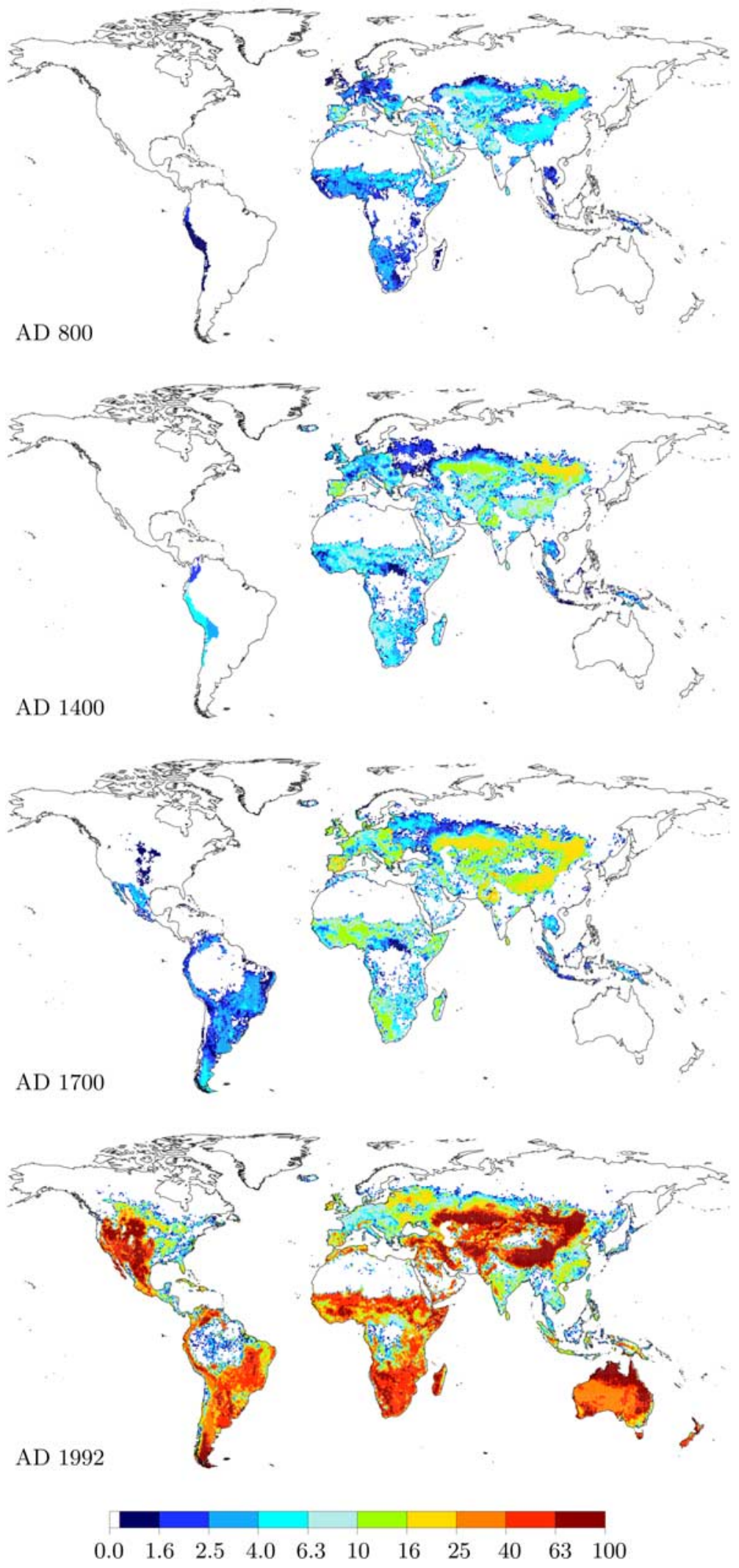

Figure 3. Global historical pasture area. Units are percent of grid cell. Values smaller than $1 \%$ are colored white. Note the logarithmic scale. 
use anything more than the simplest assumptions. Thus, our basic assumption is that in each country the ratio of area used per capita for crop and pasture did not change prior to AD 1700. This ratio, the inverse of the nutritional density, is calculated for AD 1700 from the earliest agricultural map of the 300-year series described in section 2 and our population database. Today's political borders, with a few subnational divisions where necessary, were chosen in order to be consistent with the scale of Ramankutty and Foley [1999] and to allow for easy comparison with today's statistical data. Using population as proxy for agricultural areas is not a new approach; it has been suggested, e.g., by Ramankutty et al. [2006], and has been applied to more recent times by Houghton [1999]. Possible errors resulting from this method will be discussed in section 5 .

[13] In order to convert national totals of crop and pasture area to geographically explicit information, we make a second basic assumption: The pattern of agricultural areas that we observe in each country in AD 1700 (Figures 2 and 3) is similar to earlier spatial patterns. The persistence of the agricultural pattern in each country through time is a basic assumption in claiming only that the relative intensity of agricultural use within one country does not change between pixels. In other words, this generally means that suitable areas are cultivated more intensively than less suitable ones within a country, independently of total cultivated area. The supranational pattern, however, is reconstructed independently each year from the population-based national estimates of agricultural areas. Within the accuracy of the AD 1700 global pattern, the relative importance between countries is thereby correctly represented in earlier times. While human migrations across political borders are implicitly taken into account by using country-based population data, the shift of settlement and cultivation pattern within the countries of the Americas after the European conquest is explicitly corrected for (see below).

[14] The existing time series is scaled back in time, combining the above stated key assumptions with the agricultural areas and population numbers of AD 1700 on national level (step 2 of Figure 1): The total area of agriculture of a country (cropland and pasture are each treated separately) is calculated for each year from the agricultural area per capita and historical population. The pattern of AD 1700 determines the relative fractions of the agricultural area of the pixels within a country. In countries where agricultural area in earlier years exceeds the AD 1700 value it may occur that the agricultural fractions of single pixels becomes larger than 1. For these time steps the surplus cropland or pasture area is redistributed among the other pixels relative to their fractions such that the total agricultural area of the country is conserved. Since we keep agricultural area per capita constant throughout time, we call the resulting millennium reconstruction the "persistent" estimate in the following.

[15] For some regions it is well known that agricultural pattern or practices changed severely over time. With such knowledge we had already modified the original crop time series by Ramankutty and Foley; the new patterns of agriculture we introduced are also propagated back in time when extending the time series to AD 800. For the Former Soviet Union, we continue to provide population data on subnational level in the same way as in section 2. Some more modifications had to be made in regions where not only pattern but also agricultural methods changed prior to AD 1700. This includes the establishment of agricultural tribes in New Zealand, and the colonization of the Americas. In the latter, European conquest was extremely effective in fundamentally replacing traditional cultures with the ones of the invaders. The pattern of agriculture we observe in AD 1700 thus already reflects much of the European influence. We implement these historical changes in agricultural pattern by using subnational population data, which allow to represent the change in population pattern after European conquest. We further abandon the values for agricultural area per capita derived from the AD 1700 map prior to colonization, acknowledging that the European agricultural behavior is inherently different from the native one, and use independent estimates from literature instead. Details can be found in the work of Pongratz et al. [2008].

\section{Step 3: From Agricultural Areas to Land Cover}

[16] So far, the reconstruction of a time series of agricultural areas was described, indicating area and pattern of global cropland and pasture over the course of the last millennium. For many applications involving human impact on natural ecosystems and the climate, it is essential to know the land surface properties before agriculture emerged or after it ceased. For this purpose, the reconstruction of agricultural areas can be overlaid over maps of natural vegetation. Data source and vegetation types can be freely chosen according to the application, but an allocation scheme of agriculture on natural vegetation has to be developed. One possible method is outlined below and uses 11 natural vegetation types as background to the agricultural classes. These are part of the data set published by the World Data Center for Climate and can be used in addition to the agricultural information.

[17] Step 3 in Figure 1 outlines the transformation of the reconstruction of agricultural areas into a land cover reconstruction. In this study, we use the 5 min resolution potential vegetation classification described by Ramankutty and Foley [1999], which is consistently derived from the same sources as their agricultural maps. We first reclassify the 15 existing classes into 11 natural vegetation types on the basis of the descriptions of the cover types, which in many cases is straightforward. Mixed classes are assigned to several types on the basis of bioclimatic criteria [Pongratz et al., 2008]. The reclassified data set is then aggregated from $5 \mathrm{~min}$ to 0.5 degree resolution. In a next step, agriculture is introduced into the potential vegetation map. Different methods are used for crop and pasture to determine how much each vegetation type in each 0.5 degree grid cell is affected by agriculture. For crop, we compare 5 min resolution crop cover maps (N. Ramankutty, personal communication, 2006) for each year with the reclassified $5 \mathrm{~min}$ potential vegetation. This comparison indicates what fraction of each vegetation type in a half degree pixel is lost to 
Table 1. Estimated Global Extent of Land Cover Types ${ }^{\mathrm{a}}$

\begin{tabular}{|c|c|c|c|c|c|c|c|c|c|c|c|}
\hline \multirow[b]{2}{*}{ Tropical forest } & \multirow{2}{*}{$\frac{\text { Potential Vegetation }}{22.44}$} & \multicolumn{2}{|c|}{800} & \multicolumn{2}{|c|}{1100} & \multicolumn{2}{|c|}{1400} & \multicolumn{2}{|c|}{1700} & \multicolumn{2}{|c|}{1992} \\
\hline & & 22.03 & $(22.07)$ & 21.87 & $(21.93)$ & 21.70 & $(21.78)$ & 21.22 & $(21.36)$ & 16.30 & $(18.24)$ \\
\hline Temperate broadleaf forest & 10.48 & 10.15 & (10.19) & 9.92 & $(10.00)$ & 9.87 & $(9.97)$ & 9.26 & $(9.47)$ & 5.95 & $(6.71)$ \\
\hline Temperate needleleaf forest & 15.75 & 15.61 & $(15.63)$ & 15.51 & $(15.55)$ & 15.47 & $(15.52)$ & 15.17 & $(15.27)$ & 12.36 & $(12.98)$ \\
\hline Total forest & 48.68 & 47.78 & $(47.89)$ & 47.31 & $(47.47)$ & 47.05 & $(47.26)$ & 45.65 & $(46.09)$ & 34.60 & $(37.93)$ \\
\hline Grass and shrubs & 46.79 & 44.90 & $(46.23)$ & 44.22 & (46.04) & 43.84 & (45.89) & 42.14 & (45.39) & 13.63 & $(38.89)$ \\
\hline Tundra & 4.08 & 4.07 & $(4.07)$ & 4.06 & $(4.07)$ & 4.06 & $(4.06)$ & 4.05 & $(4.06)$ & 2.94 & $(3.98)$ \\
\hline Total natural vegetation & 99.55 & 96.75 & $(98.19)$ & 95.60 & $(97.58)$ & 94.95 & $(97.22)$ & 91.84 & $(95.54)$ & 51.16 & $(80.80)$ \\
\hline Crop & - & 1.36 & $(1.36)$ & 1.97 & $(1.97)$ & 2.33 & $(2.33)$ & 4.01 & $(4.01)$ & 18.76 & $(18.76)$ \\
\hline Pasture & - & 1.44 & $(0.00)$ & 1.98 & $(0.00)$ & 2.27 & $(0.00)$ & 3.70 & $(0.00)$ & 29.63 & $(0.00)$ \\
\hline Total agriculture & - & 2.80 & $(1.36)$ & 3.95 & (1.97) & 4.60 & $(2.33)$ & 7.71 & $(4.01)$ & 48.39 & $(18.76)$ \\
\hline
\end{tabular}

${ }^{\text {a}}$ Units are $10^{6} \mathrm{~km}^{2}$. Values in brackets are estimates disregarding pastures.

crop. Prior to AD 1700, the proportions of area lost to crop between the natural types are kept constant as far as possible. Only in cases where the crop area assigned to a certain vegetation type exceeds its area, the surplus crop area is proportionally distributed on the other types. For pasture, where no subgrid information is available, we assume a certain land cover priority. Pasture is first allocated on grass as far as possible, then on the area of the woody vegetation types. This procedure reflects human behavior of minimizing effort: Clearing of forest is generally not performed if sufficient natural grassland is available for grazing [Houghton, 1999; Ramankutty et al., 2006]. The resulting changes in land cover over the course of the last millennium can be found in Table 1, where the natural vegetation types are aggregated to 5 more general classes.

[18] Abandoned agricultural area is attributed to the type of natural vegetation indicated by the potential vegetation data set. The different structure of this secondary vegetation compared to primary one, specifically the gradual regrowth of vegetation, needs to be adequately represented when the proposed land cover reconstruction is used to derive land surface properties. Many biosphere models allow for these gradual transitions. In such cases errors are limited to abandoned agricultural area that does not return to potential vegetation, e.g., where forest reestablishment is inhibited through degraded soil conditions.

\section{Assessing Uncertainty and Validity}

[19] The method developed in this study relies on only few, basic assumptions when historical sources and modern estimates fail to provide the necessary information. The aim is to keep methods, results, and uncertainties at any time straightforward and comprehensible. In the following, we discuss sources of possible errors and assess uncertainties associated with data and method.

\subsection{Inclusiveness of the Millennium Reconstruction}

[20] This study focuses on anthropogenic land cover change that permanently changes the type of vegetation, taking into account the permanent expansion and abandonment of cropland and pasture. Two important land use types, however, are not included:
[21] 1. Wood harvesting is not considered in this study. Our reconstruction can be combined with wood harvest data once such statistics become available for preindustrial times, but it should be kept in mind that the clearing of forest for timber or fuelwood is not an entirely independent land use alongside agriculture. A part of the area cleared for wood harvest is subsequently used for agriculture, and another part is quickly regrown in a system of managed forest and does therefore not represent a permanent change of the type of vegetation.

[22] 2. The long-term fallow area that results from shifting cultivation is not covered by this study. A sensitivity analysis [Hurtt et al., 2006] showed that the omission of shifting cultivation may lead to a significant underestimation of secondary land area created by agriculture, but the very high resolution data needed to resolve such small-scale processes is usually not available for large regions. However, shifting cultivation only increases the area undergoing gross transition, while net transition, as represented by our data set, is unaffected. Similarly, the representation of wood harvest would only alter the area of undisturbed vegetation, but not the area estimates of cropland and pasture derived in this study. Therefore, our results for cropland and pasture remain valid within the accuracies discussed in the following, as long as no subnational and subgrid information is derived.

\subsection{Validation of the Base Data AD 1700 to 1992}

[23] Ramankutty and Foley [1998] compared their remote-sensing-based cropland map of 1992 to three other estimates and conclude that their data set provides a "reasonably accurate and quantitative depiction of croplands across the globe". The SAGE maps have also been compared to the HYDE data for cropland in both present and historical times (for details, see Klein Goldewijk and Ramankutty [2004] and Ramankutty et al. [2006]). They are found to be generally consistent with HYDE in representing cropland over the last 300 years. A strong caveat of this comparison is the fact that the two data sets are not entirely independent and partially rely on the same input data. The SAGE time series has further been proven to 
represent common knowledge about the evolution of cropland in different parts of the world [Ramankutty and Foley, 1999].

[24] Few independent data sets exist that could be used to validate the pattern of pasture. It is often impossible to distinguish between pristine grasslands and such used for grazing (pasture) in observation data, and classification strongly depends on subtleties in definition. When compared to the HYDE data (revised version 3.0, K. Klein Goldewijk, personal communication, 2007), the present-day pasture extent of Foley et al. [2003] agrees well in Europe, America and Africa, though in the latter the HYDE data concentrates pasture more strongly in the Maghreb coast and the Sahel. Some differences exist in the Middle East. Especially the semidesert and desert of the Arabian peninsula show much higher intensities of pasture in the HYDE data, while the SAGE map is more closely coupled to the maximum possible vegetation cover. We believe that this is the more appropriate pattern for historical times, where population pressure was low and less suitable areas did not have to be included into agricultural activity. The interior of the Australia continent is less intensely used for pasture in the SAGE data, but this discrepancy is unimportant for historical times as Aboriginal agricultural activity was very low. The most extensive pasture lands in Mongolia and Tibet are identified in both SAGE and HYDE 3.0, but with a higher intensity in the SAGE data. In our reconstruction, this high intensity reflects back to historical times.

[25] We conclude that the overall pattern of cropland and pasture of Ramankutty and Foley [1998, 1999] and Foley et al. [2003] are in good agreement with other studies. This is an important point, as historical patterns are derived from present day data in both the SAGE approach and our method and errors would propagate to earlier times. Concerning total agricultural areas, some uncertainty exists not only for past, but also present times. In absolute numbers, the 1992 Ramankutty and Foley map used in this study (including the modifications described in section 2) shows a cropland area of $18.8 \cdot 10^{6} \mathrm{~km}^{2}$, while estimates by Richards [1990] for the year 1980 are $15.0 \cdot 10^{6} \mathrm{~km}^{2}$, by Houghton [1999] for the year 1990 are $13.6 \cdot 10^{6} \mathrm{~km}^{2}$, and by Klein Goldewijk [2001] for the year 1990 are $14.7 \cdot 10^{6} \mathrm{~km}^{2}$ (note that all estimates partially rely on the same input data). The pasture map used in this study shows an area of $29.6 \cdot 10^{6} \mathrm{~km}^{2}$ as opposed to the estimate of Klein Goldewijk [2001] for the year 1990 of $34.5 \cdot 10^{6} \mathrm{~km}^{2}$. Obviously, notable uncertainties exist despite the growing availability of ground- and satellite-based observations and international statistical databases. We cannot assume that data uncertainties are any smaller between AD 1700 and 1992 than at present. As this time series is also the base data for our reconstruction, this uncertainty is passed on to all earlier time steps.

\subsection{Uncertainty of the Population Data}

[26] Despite the long tradition of demographic research, no outright consensus exists concerning quantitative estimates of historical population, especially for times earlier than the 18th century. Global numbers differ by up to a factor of two for the first millennium AD; regional estimates can be even more disputed. The data set predominantly used in this study [McEvedy and Jones, 1978] is largely acknowledged in recent literature and stands out through its consistency and high spatial and temporal resolution. The uncertainties introduced by the choice of this specific population database are estimated in the following.

[27] The population database of this study is compared to six other historical estimates (Clark [1967], Biraben [1979], Maddison [2001], and high, mean, and low estimates by Durand [1977]). For the Americas, we further include the original data from McEvedy and Jones [1978] without our modifications. Data for the years AD 1000, 1500 and 1700 are used in aggregated form for four regions following Maddison [2001] (Table S1). ${ }^{1}$ There is good agreement between the studies with respect to Europe and Asia, where estimates differ by less than a factor of 2 even for early years. Not surprisingly, however, large differences exist for Africa and the Americas, where much of the continents was still unexplored by the end of the 17 th century. Still in debate, for example, is the number of native Americans prior to European arrival, where estimates range between 14 and 63 million, as well as the rate of population growth before.

[28] The population dynamics of the temporally highly resolved data used in this study are superimposed on the alternative estimates. Then, for each year and each region the two data sets are chosen that give the highest and lowest changes in population relative to their AD 1700 value. This method thus results in an uncertainty range around the population estimates used for the millennium reconstruction. It is important to note that the extreme ranges do not represent consistent time series of likely alternative scenarios. Rather, they indicate the entire range of possible estimates of agricultural areas for a given year, where the outer bounds can only be reached for a certain time period throughout the millennium, if at all. The maximum uncertainty range we assign to the persistent estimate because of uncertainties in population estimates, based on the described approach, for the year AD 800 is 1.1 to $1.6 \cdot 10^{6} \mathrm{~km}^{2}$ around the persistent estimate of $1.4 \cdot 10^{6} \mathrm{~km}^{2}$ for crop, and 1.1 to $1.7 \cdot 10^{6} \mathrm{~km}^{2}$ around the estimate of $1.4 \cdot 10^{6} \mathrm{~km}^{2}$ for pasture. In relative terms, the largest underestimation that could occur in AD 800 due to errors in the population data used in this study is in the Americas. Here, the high estimate of Durand [1977] does acknowledge that there has been significant decrease in population with European conquest, but believes in steadily high population before that. The largest overestimation of our study could occur in Africa. Here, Biraben [1979] suggests much stronger population dynamics prior to AD 1700 than all other data sets.

\subsection{Effects of Agrotechnical Improvements}

[29] A major assumption of our approach in reconstructing historical agricultural areas is that the ratio of agricultural areas per capita did not change prior to AD 1700. Agricultural areas per person is the inverse of nutritional density and corresponds to land (not labor) productivity (per area yields) in the absence of major dietary changes and

\footnotetext{
${ }^{1}$ Auxiliary materials are available in the HTML. doi:10.1029/ 2007GB003153.
} 

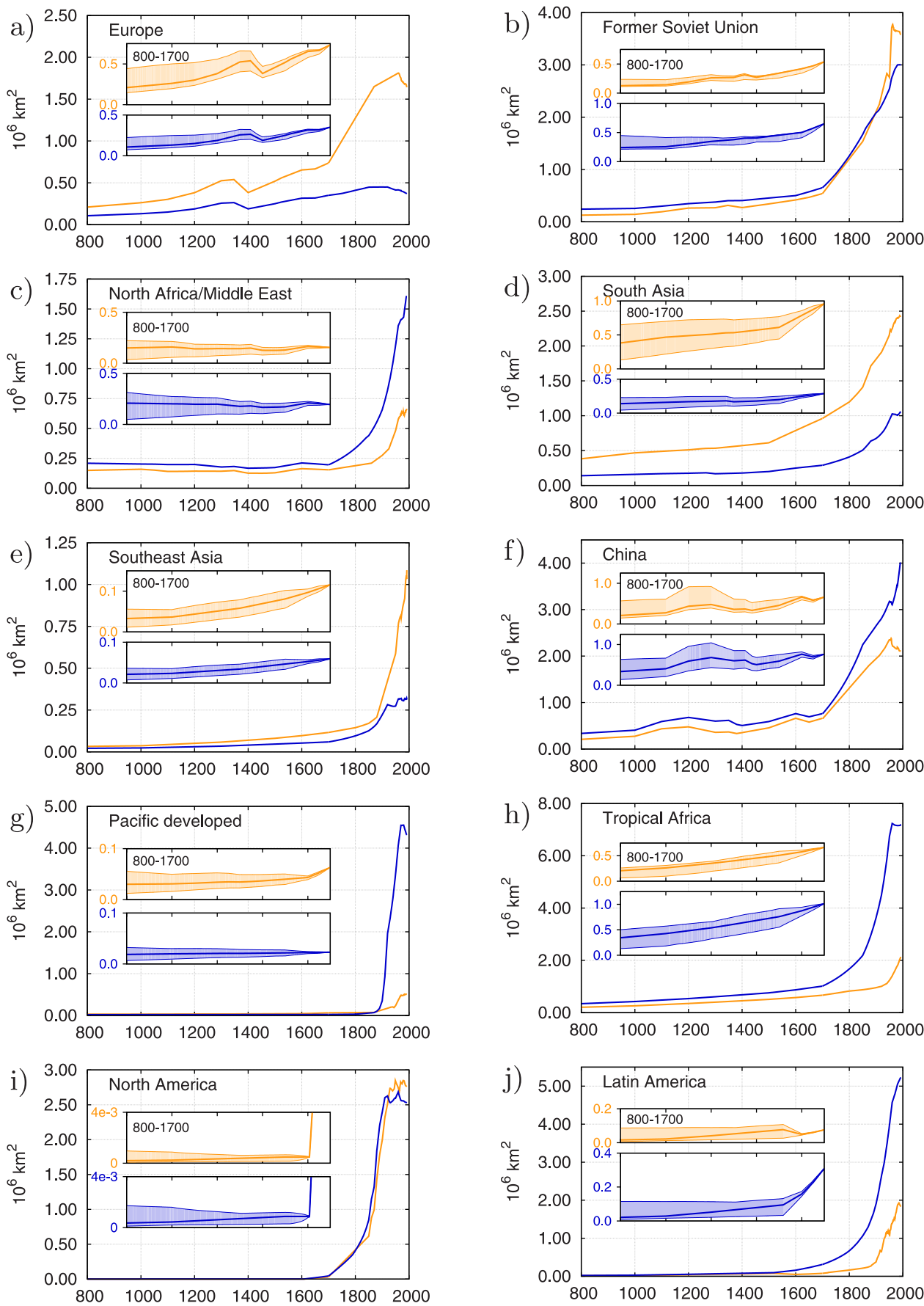

Figure 4. Total area of crop (orange) and pasture (blue) for the 10 world regions defined by Houghton et al. [1983] from AD 800 to 1992 (in $10^{6} \mathrm{~km}^{2}$ ). The insets show the time period AD 800 to 1700 at different scale and with shaded area indicating the uncertainty range (see text for explanation).

trade. Dietary changes and trade are considered to be minor drivers of changes in agricultural areas in the time period under investigation. Trade, specifically, was largely limited to high-value products such as silk, wool, and spices, unless water transport became possible, as costs of transport prior to the 19th century were too high to move general foodstuff [Grigg, 1974]. Theory predicts that land productivity increases within a civilization as agrotechnical innovations are continuously triggered through population pressure and shortages [Boserup, 1965; Sieferle, 1997], but published data is not sufficiently available for use in a consistent global analysis and is frequently in contradiction to theory [Slicher van Bath, 1963].

[30] Nevertheless, an estimate of the uncertainties of the persistent estimate of the millennium reconstruction is desirable. For this, we recalculate crop area within a maximum range of possible changes in per capita values of cropland. In these values, we try to not only include 

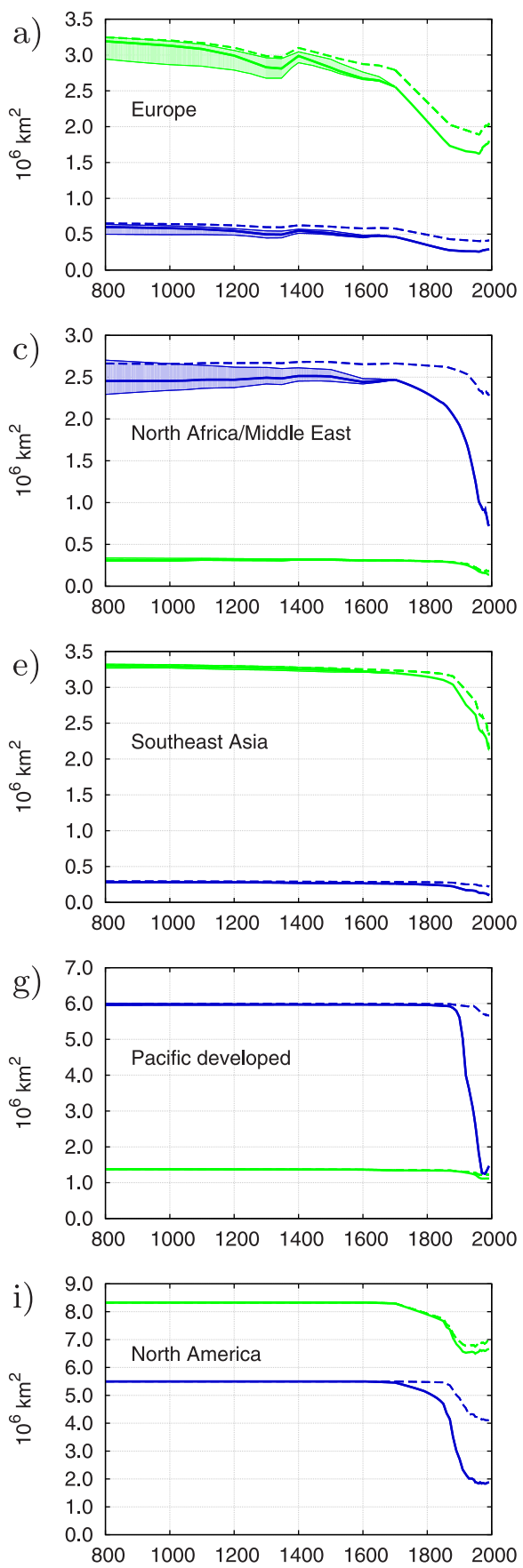
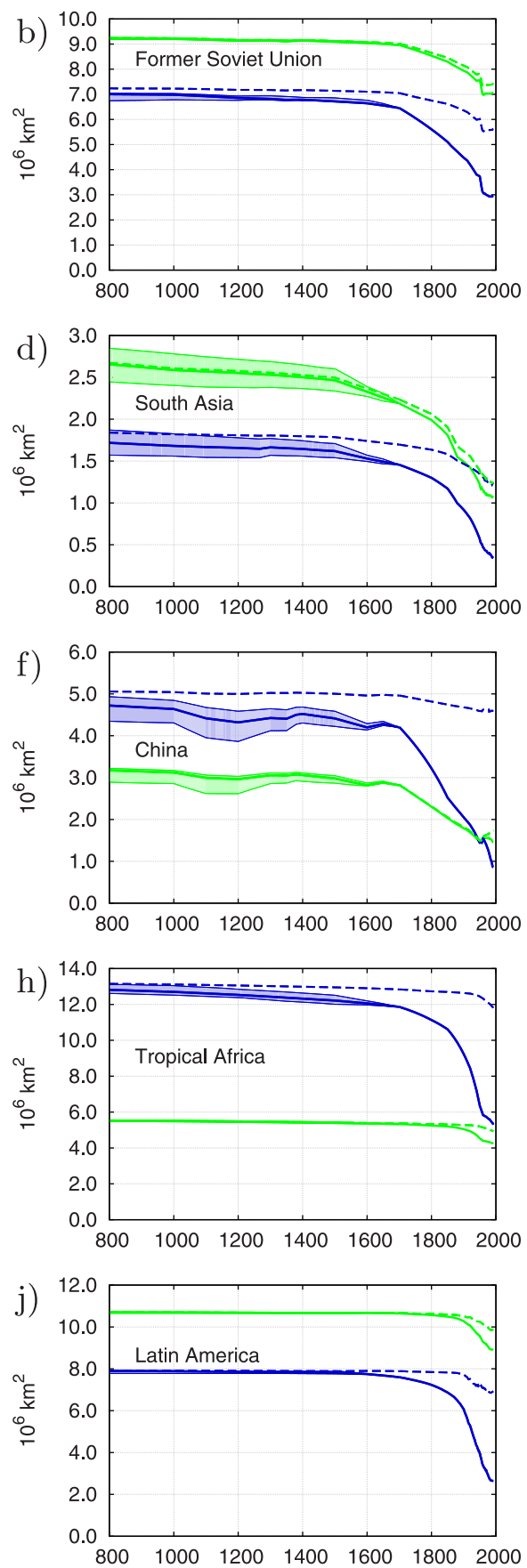

Figure 5. Total area of natural vegetation: forest (green) and natural grassland, shrubland, and tundra (blue), for the 10 world regions defined by Houghton et al. [1983] from AD 800 to 1992 (in $10^{6} \mathrm{~km}^{2}$ ). Shaded area indicates the uncertainty range (see text for explanation). Dashed lines are land cover change due to cropland only.

agrotechnical progress, but also regression due to land degradation and socioeconomic disturbances, changes in crop types, and changes in the fraction of population incorporated in an agricultural system for those regions where we know that these factors play a nonnegligible role. On the basis of these factors, we try to give an upper and lower boundary of possible changes in per capita cropland. Where available, we base our estimates on quantitative data, such as yield ratios from Slicher van Bath [1963] for European countries and nutritional densities cited by Grigg [1974] for East Asian countries. Where quantitative data is missing, we classify regions as one of three cases on the basis of the information of Grigg [1974] and Vasey [1992]: regions with general decrease in per capita cropland values (range of 0.7 to 1.7 in $\mathrm{AD} 800$ relative to $\mathrm{AD} 1700$ around the persistent 
estimate), with no change $(0.5-1.5)$, and with general increase $(0.3-1.3)$ (see Table S2; for details, see Pongratz et al. [2008]). With these numbers, the time period under consideration is characterized as a period where the overall pace of technological change in farming has been "remarkably slow" [Grigg, 1974, p. 50] and most of the preindustrial increases in crop and animal production occurred as a result of increases in agricultural areas [Ruttan, 2002].

[31] Changes in the per capita use of pastures have not been assessed for historical times in literature. Here, we generally use the same ranges for pastures as for cropland. Most factors affecting changes in cropland per person will also affect the use of pasture. Changes in productivity will be less pronounced than for crop, but the general trend may be similar, since many agrotechnical improvements such as manuring can also be applied to forage crops and the number of draught animals per capita is linked to cropland productivity.

[32] The maximum uncertainty range we assign to the persistent estimate due to changes in per capita agricultural areas, for the year $\mathrm{AD} 800$, is 0.8 to $2.2 \cdot 10^{6} \mathrm{~km}^{2}$ around the persistent estimate of $1.4 \cdot 10^{6} \mathrm{~km}^{2}$ for crop, and 0.8 to $2.1 \cdot 10^{6} \mathrm{~km}^{2}$ around the estimate of $1.4 \cdot 10^{6} \mathrm{~km}^{2}$ for pasture. Changes in the agricultural systems of the world thus introduce a significantly higher uncertainty in our approach than the decision for a specific population data set. Except for the Americas, this statement also holds true at regional level. This difference can largely be explained by the fact that population data itself is less uncertain than information on per capita agricultural area. The reasons for this include a greater administrative interest in documenting population throughout history in combination with a much better agreement on the definition of "population" than of "agricultural area" or "yields". Furthermore, the spatial coverage is higher for population estimates, which are usually documented at a regional scale. On the other hand, information on the per capita demand of agricultural area has to be extrapolated from local measurements and qualitative descriptions, which was done in a conservative way in this study. For the following analysis of historical land cover change, we combine both uncertainty factors, per capita agricultural areas and population, in a way that results in the maximum possible range at every time step in every part of the world. Joining highest agrotechnical progress with lowest population growth and vice versa give possible, but unlikely estimates of agricultural areas. This range of uncertainty assigned to the persistent estimate therefore does not indicate a range of equal preference, which would be much smaller. Instead, it is intended to define limits of possible errors in the estimates caused by our approach. We did not assign an uncertainty range to the base data $\mathrm{AD}$ 1700 to 1992 , but it should be kept in mind that errors in the maps of AD 1700 propagate back in time (section 5.2).

\section{Changes in Land Cover AD 800-1992}

[33] We present our reconstructions in two ways: The full spatial information is depicted in the maps for historical crop and pasture in Figures 2 and 3, shown for four time slices. More information about the temporal evolution of cropland and pasture are presented in Figures 4 and 5. Here, the total areas of the agricultural types and the natural vegetation types are plotted for 10 world regions. The persistent estimates are surrounded by the range which was determined from the uncertainties in our method associated with population data as well as changes in per capita agricultural areas (see section 5). Additionally shown with the natural vegetation types is the persistent estimate for land cover change due to the expansion of cropland only, disregarding pasture. It is thus possible to separate the impact of changes in cropland on natural vegetation from the impact of changes in pasture.

[34] We can compare the millennium reconstruction against the common knowledge about the history of agriculture in order to test its plausibility and interpret our results. The map for AD 800 (Figure 2) clearly highlights the regions with the longest history of agriculture: High intensities of crop cultivation are found in the Mediterranean, the Fertile Crescent, and India. Large areas of cropland are also deduced for China. In all these regions, the domestication of crops or the spread of crops into the region had taken place thousands of years ago [Vasey, 1992]. On the other hand, many parts of the world show little human impact in the map of AD 800. Agriculture had developed early also in the Americas, but intensity remained low outside the centers of high cultures until Europeans arrived [Grigg, 1974]. Most of central Asia was not settled until the 19 th century, and the agricultural tribes in Australasia were few and low in numbers [McEvedy and Jones, 1978]. Much of Africa must still have been pristine in AD 800, but the continent competes in our reconstruction with India for the strongest and steadiest growth of cropland over all centuries in preindustrial times. At the same time, other regions experience repeated setbacks in their agricultural history, driven by political and economic instability as in China and Europe, by epidemics as in Europe and the Americas, or changes in cultural habit and environmental conditions as in southwest Asia and the Mediterranean [Grigg, 1974]. By their impact on population, these events are captured by the millennium reconstruction.

[35] The distribution of pasture is quite different from that of cropland in both historical and present times (Figure 3). Some of the most important areas are found in AD 800 in Europe and southwest Asia. Here, animals had been used early already as draught animals [Grigg, 1974]. Vast areas of pasture are found in the steppe and semideserts of Asia and the savannas of Africa. In these regions, animals were rarely incorporated in crop production, and nomadic pastoralism prevailed in preindustrial times, often persisting until today [Grigg, 1974]. As for crop production, general cultural development and historical events imprint their dynamics on the extent of pasture. The many factors that contribute to both pattern and changes of the extent of crop and pasture are highly variable through time and space.

[36] Table 1 summarizes the human-induced changes of land cover on a global scale. By AD $800,2.8 \cdot 10^{6} \mathrm{~km}^{2}$ of natural vegetation have already been transformed to agricultural land, which is about $3 \%$ of the area potentially covered by vegetation. This transformation was almost 
equally caused by cropland and pasture, but both types of agriculture affected quite different ecosystems. On the one hand, $0.8 \cdot 10^{6} \mathrm{~km}^{2}$ of pristine forest were cleared for the cultivation of crop, large parts of it in the temperate and the tropical broadleaf deciduous forests. On the other hand, $1.3 \cdot 10^{6} \mathrm{~km}^{2}$ of pastures are located on areas that were naturally covered by grassland anyway and are thus not associated with major changes in the type of vegetation. By AD 1700, agricultural area has extended to $7.7 \cdot 10^{6} \mathrm{~km}^{2}$ : $3.0 \cdot 10^{6} \mathrm{~km}^{2}$ of forest have been cleared, $85 \%$ of this for cropland, the other $15 \%$ for pasture; $4.7 \cdot 10^{6} \mathrm{~km}^{2}$ of grassland and shrubland are under human use, but only $30 \%$ are used for the cultivation of crop. Grassland, temperate and tropical broadleaf deciduous forest remain the most strongly affected ecosystems. Within the next 300 years, total agricultural area rises to $48.4 \cdot 10^{6} \mathrm{~km}^{2}$, especially pasture expands. The ecosystems that lose the largest areas to human use are now natural grasslands, summergreen shrubs, temperate and tropical broadleaf deciduous forest and tropical evergreen forest. Between AD 800 and AD 1700, there were thus $4.9 \cdot 10^{6} \mathrm{~km}^{2}$ of natural vegetation brought under agricultural use, compared to $40.7 \cdot 10^{6} \mathrm{~km}^{2}$ in the following three centuries. Despite these largely different values we should not consider the land cover change during the early centuries of our reconstruction as irrelevant. First, the expansion of agriculture during these 900 years was likely much greater than during the millennia that had passed since the Neolithic Revolution, considering the strong population growth during this period and the steadily growing dominance of agriculture over hunting and gathering cultures. Secondly, there are significant differences between different parts of the world. Some regions developed amazing rates of agricultural expansion that cannot be discerned on a global scale, and regional dynamics, including decline of agriculture, are remarkable. In the following subsections, we present the reconstruction of agricultural areas on the regional level in the context of agricultural history. We will mainly focus on the time period prior to AD 1700; for details on the last 300 years we refer the reader to Ramankutty and Foley [1999].

\subsection{Europe and Former Soviet Union}

[37] Farming and herding were spreading westward from the ancient centers of agriculture in southwest Asia to Europe and reached the shores of the North and Baltic seas as well as the Iberian peninsula by 4000 BC [Grigg, 1974]. With about $3.2 \cdot 10^{5} \mathrm{~km}^{2}$ of cropland and pasture in AD 800 , Europe had become one of the agriculturally important regions of the world by early medieval times (Figure 4). European agricultural colonization progressed fast until the 14th century and agrotechnical advances opened up land that was previously considered unsuitable for agricultural use [Crombie, 1977]. The steady increase in agricultural area and the corresponding clearing of forest came to a sudden halt with Black Death, the plague epidemics AD $1347-1353$ that killed a quarter to a third of the population. In the following decades an estimated $2.3 \cdot 10^{5} \mathrm{~km}^{2}$ of farmland were abandoned and allowed for some regrowth of forest (Figure 5a). Fast rates of land cover transformation were returned to in the 15 th century, but agricultural expansion stagnated again in the early 17 th century in Europe as a whole as a consequence of several regional processes, including the Thirty Years War and economic crises in the Mediterranean countries. A rapid expansion of cropland on forested areas dominated until the middle of the 19 th century.

[38] The large uncertainties of agricultural estimates in Europe are a consequence of the uncertain changes in land productivity rather than disagreement in population numbers. Technological progress was fast, especially in the northwestern countries, but at the same time centuries had to pass before a useful innovation found widespread application, and more marginal land had to be brought under cultivation [Vasey, 1992]. Still, we estimate total agricultural areas in the early centuries of the reconstruction more probably at the low than at the high end of the displayed uncertainty range.

[39] While rates of change slowed down in most of Europe in recent decades and even allowed for regrowth of natural vegetation, notable land cover changes occurred in the FSU. In this region agriculture had mainly been restricted to the European part prior to the 19th century, when for the first time significant number of settlers started to colonize Siberia. Only Russian Turkestan looks back on an ancient history of agriculture with a strong predominance of pastoralism [Vasey, 1992]. During 1940-1960 rapid land cover conversions took place in the FSU associated with the opening up of the "New Lands" [Ramankutty and Foley, 1999]. While agricultural expansion took place mainly at the expense of forested regions in Europe, expansions in the FSU affected both forests and steppe and reduced natural grasslands to a fifth of their potential area.

\subsection{North Africa and Middle East}

[40] In southwest Asia lies one of the birthplaces of agriculture. Wild cereals were harvested already in the 10th millennium BC and seed agriculture developed, associated early with the use of ploughs and draught animals [Grigg, 1974]. Intensive agriculture in AD 800 is restricted, however, to the Mediterranean coast and Anatolia, where climate is more favorable, and to the irrigated fields of Egypt and the Fertile Crescent (Figures 2 and 3). The latter is the most intensely cultivated region worldwide at the beginning of our reconstruction, with crop fractions of up to $50 \%$. This prominent role, however, is lost during the next few centuries, and a multitude of reasons led to stagnating agriculture also in the other regions of the Middle East and North Africa (Figure 4c). In Persia and Anatolia, Turkish invasions had negative effects on peasant activity, while North Africa was affected by the Bedouin invasion (11th century), the plague (14th century), and the Mediterranean economic recession (17th century) [McEvedy and Jones, 1978]. In Egypt, all land was already exploited as far as technology allowed. Crop and pasture thus remained at a relatively low extent for many centuries until population gradually grew from the 18 th century onward. With pastoralism being the dominant form of agriculture, much natural grassland was now used for grazing (Figure 5c). Crop production became more important in the 20th century, 
associated with a steep increase of population, and with it woody vegetation was reduced.

[41] The long history of cultivation in this region most probably degraded land productivity in many regions, with salinization becoming a common problem in irrigated areas. Permanent agriculture was frequently given up in favor of nomadism in times of economic recession and warfare [Grigg, 1974]. Our persistent estimate thus lies at the higher end of crop estimates, and uncertainties are large for natural and managed grassland areas. Errors in the population estimates play a minor role only: though absolute numbers are still subject to dispute, growth rates are rather similar in all literature estimates.

\subsection{South Asia and Southeast Asia}

[42] The Indian subcontinent experienced peasant settlement in the 4th millennium BC in the Indus valley and around the 1st millennium BC in the Ganges valley [Grigg, 1974]. By AD 800, south Asia was the major player in global crop production with about $4.0 \cdot 10^{5} \mathrm{~km}^{2}$ of cultivated land (Figure 4d). Crop areas grew steadily, though at moderate pace first. Population most certainly has been set back several times throughout the centuries, but historical evidence is sparse [McEvedy and Jones, 1978]. A significant part of the indicated uncertainties must thus be attributed to demographic data. From the 16 th to the 19th century agricultural expansion accelerated, significant amounts of forest were cleared for cropland, and grass and shrubland were used for grazing (Figure $5 \mathrm{~d}$ ). Under European control and after independence, the pattern became more complex with agricultural expansion set off by abandonments in various parts of India [Ramankutty and Foley, 1999].

[43] Compared to the Indian subcontinent, agricultural activity was rather low in Southeast Asia in AD 800 and remained so for the next thousand years. On the Malay Archipelago peasant population has always been concentrated on the southern islands [Grigg, 1974], a pattern reflected in Figures 2 and 3. Much of the increase in cropland area that happened in Southeast Asia (Figure 4e) must be attributed to the spread of wet rice, which had been introduced from China or India about 2000 years ago [Grigg, 1974]. Rice also has a key role in the high expansion rates of crop in the mainland countries in the 19th and 20th century. In recent decades, the Southeast Asian region has one of the highest deforestation rates globally. Pasture areas are small compared to cropland in Southeast Asia with a total of $3.1 \cdot 10^{5} \mathrm{~km}^{2}$ in 1992 , but some of the highest stocking rates of the world are found in these countries [Asner et al., 2004].

\subsection{China}

[44] An independent development of seed agriculture took place in northern China in the 5th and 6th millennia $\mathrm{BC}$ including the domestication of pigs, while tropical vegeculture was practiced further south [Grigg, 1974]. On the basis of these traditions, it is not surprising that Chinese crop area was large by AD 800 , estimated at $2.1 \cdot 10^{5} \mathrm{~km}^{2}$. Large-scale migration from the Yellow River south in the preceding centuries had probably led to a crop pattern similar to today, covering much of the eastern part of the country. Not reflected in our pattern, however, is the following further concentration of agriculture in the southeastern areas. With it, agricultural methods changed notably, with increasing focus on rice and the introduction of doublecropping. The possible range of crop area prior to the 14th century is thus large, and the persistent estimate is at its lower end (Figure 4f). Population data contributes only marginally to the uncertainties thanks to meticulous dynastic censi. Two dramatic events interrupted the otherwise strong growth of population and agriculture: the country lost about a third of its population in the course of the Mongol invasions starting in AD 1211, and again about a sixth of its population in the upheavals after the fall of the Ming Dynasty in 1644 [McEvedy and Jones, 1978]. Thereafter, growth was resumed at unprecedented pace, and half of China's natural forest cover was transformed to cropland.

[45] The $3.4 \cdot 10^{5} \mathrm{~km}^{2}$ of pasture in AD 800 is almost exclusively located in Mongolia and Tibet, where herding was the traditional form of agriculture well into the 20th century. The large uncertainties of the estimates should be seen as tribute to nomenclature: nomadism makes it difficult even today to define permanent pastures. The expansion we see is largely at the expense of natural grassland or tundra vegetation (Figure 5f).

\subsection{Pacific Developed}

[46] A clear break occurs in the late 19th century in the developed countries of the Pacific, with very little agricultural area and dynamics over the preceding millennium and a steep increase of agriculture, mainly pasture, afterward (Figure 4g). In Japan, the agricultural area needed per capita in AD 1700 is extraordinarily small, as fish has been a major part of the traditional diet and the main crop, rice, was cultivated with high nutritional density [Grigg, 1974]. We see notable increases in agriculture only after 1870. After 1945, Australia became the driving force of land cover change in the Pacific developed region. Crop expanded in the 19th century in southeast Australia, later in Western Australia, affecting grass as well as woody ecosystems. An additional $4.1 \cdot 10^{6} \mathrm{~km}^{2}$ of pasture exist in 1992 in Australia, making it the country with the most land area in pasture systems. For a large part natural grasslands were used as pastures, but also shrubland with woody vegetation, which was not always permanently cleared for herding. The reduction in shrubland seen in Figure $5 \mathrm{~g}$ for the last century may thus be overestimated when defining pastures as open grassland. New Zealand shows a similar trend in crop and pasture as Australia, though at much smaller absolute numbers.

\subsection{Tropical Africa}

[47] By 1700 the region south of the Sahel was still largely unexplored outside the coastal regions and population numbers and agricultural habits are still a matter of dispute. Vegeculture must have existed from the 5th millennium BC onward in West Africa and cereal cultivation developed in the Horn region. The northern savannas were agriculturally used by the 3rd or 2nd millennium BC [Grigg, 1974]. The Bantu expansion is one of the key 
factors in spreading cereal cultivation, pastoralism and iron technology throughout much of sub-Saharan Africa [Grigg, 1974; Hanotte et al., 2002], and with it the pattern of agriculture may have been subject to some change especially in the early centuries of our reconstruction. The uncertainty range suggests lower values for cropland and pasture extent to account for the possibility that Bantu culture gradually replaced cultures based on hunting and gathering. Much of the uncertainty in this part of the world, however, is due to contradictory population estimates ranging, e.g., between 25 and 50 million for AD 1000 (see Table S1).

[48] In general, we observe a steady increase of agriculture in all countries of tropical Africa, which comprises the most different cultures, some of which are almost exclusively depending on herding while others mix husbandry with significant cultivation [Vasey, 1992]. Animal husbandry is and has always been a significant sector of agriculture in this part of the world, and pasture features as the dominant type of agriculture in West Africa, the Horn and southwest Africa in the early centuries of our reconstruction (Figure 3). Grazing focuses on the vast savanna regions and it seems reasonable to assume that their woody fractions are notably affected only during the last two centuries, with the onset of exponential population growth and increasing pressure on ecosystems. Figure $4 \mathrm{~h}$ shows that the expansion of pasture came to a halt in the 1960s, while croplands further increased. The pattern of cropland changed to form new centers in South Africa, the Lake Victoria region, and Nigeria, though much of today's crop cover in tropical Africa still remains under lowintensity subsistence farming [Ramankutty and Foley, 1999].

\subsection{The Americas}

[49] While there was a lively dispersal of domesticated plants and animals across the Old World, the Americas developed their very own forms of agriculture. First evidence of plant domestication stems from Meso-America and coastal Peru in the 6th and 5th millennium BC [Grigg, 1974]. In Central and South America, notable cropland intensities developed only within the high cultures, while outside these regions low-intensity swidden cultivation was practiced (Figure 2). Crop areas grew to some $0.8 \cdot 10^{5} \mathrm{~km}^{2}$ in our estimates by $\mathrm{AD} 1500$. Pasture at the same time is estimated to be $0.9 \cdot 10^{5} \mathrm{~km}^{2}$ and located mainly on the grasslands in the Andes, where some peoples are known to have kept cameloids [Vasey, 1992]. The uncertainty range around these estimates, however, is large despite the small total area, owing to the historians' dispute about preColumbian population (section 5.3). Significant agricultural areas must have been abandoned with the reduction of the native population by European weapons and diseases, seen as a decrease in crop estimates in Figure 4j. Under European rule started a large-scale transformation of natural vegetation for crop cultivation as well as for ranching, and agricultural areas were shifted from the west toward the east coast (Figures 2 and 3). Much of the natural grasslands of the steppe and savanna is used today for grazing [Vasey, 1992] (Figure 5j).

[50] In North America, some clearing of natural vegetation took place in a kind of swidden system, but wild food remained important [Vasey, 1992]. The spatial pattern and the distinct cultures of the different indigenous peoples in North America are not resolved by our global reconstruction, which should thus not be applied in small-scale studies in this part of the world prior to colonization. The new diseases following first European contact brought population growth to a halt, but North America was affected less severely than Central and South America. With the colonization in the 17th century the European form of agriculture was introduced to the east coast and subsequently spread west. Growth rates of agricultural area are high in the following centuries as a result of both increasing population and the growing dominance of agriculture over hunting and gathering. While the crop maps of Ramankutty and Foley [1999] are based on state-level data from 1850 onward and are thus able to display this relocation, our algorithm for historical pasture is based on national totals. Some of the grassland in the Great Plains and further west, which Figure 3 classifies as pasture in AD 1800, was thus probably still pristine, and pastures were located further east instead. Robust features, after centuries of very low agricultural activity, are the steep increase of cropland and pasture extent on a continental scale during the 18th and 19 th century with stagnating numbers in the 20th century.

\section{Conclusion}

[51] This study has presented a consistent approach to reconstruct global historical areas of cropland and pasture for time periods where agricultural data is scarce. Countrybased population estimates have been used as proxy for agricultural activity. A method, based on few, basic assumptions, has been developed that allows to consistently translate these population data into estimates of extent of cropland and pasture. Its transparency allows to easily identify possible errors in each region, and we have tried to specify the uncertainties associated with our approach. Data sets for the highest and lowest possible agricultural estimates have been provided that can be used for sensitivity studies in further applications. The reconstruction shows that global land cover change was small between AD 800 and $\mathrm{AD} 1700$ compared to industrial times. Compared to previous millennia, however, land cover change during the preindustrial time period of the last millennium must have been large, and notable fluctuations and distinct histories of agriculture are revealed on regional scales.

[52] There are no global data available that could be used to validate our reconstruction. Local studies can be found for specific time periods, but the subnational scale is not the proper basis for comparison. Except for a few regions, no subnational data were included in our approach, so that meaningful tests can be performed only at the country level or higher. Once independent estimates of historical agricultural extent from proxies such as pollen profiles, archeological evidence, and historical records become available for larger regions, we hope to compare our reconstruction against these estimates. The results of the millennium reconstruction are, however, in general agreement with common knowledge about the history of agriculture, and we are confident that our approach captures the global 
pattern of changes in agricultural areas and gives a sound approximation of the regional dynamics.

[53] In addition to reconstructing historical agricultural areas, estimates of human-induced changes in natural vegetation cover have also been derived. They provide a better picture of what types of vegetation were transformed to cropland and to pasture. Our estimates show that up to AD 1700 temperate and tropical broadleaf deciduous forests were most severely affected by crop cultivation, while large areas of natural grassland were used as pasture.

[54] The history of agriculture and anthropogenic land cover change is interesting in its own right. Additionally, its knowledge is an essential prerequisite to assess early human impact on the environment. In combination with ecosystem and climate models, geographically explicit data sets like the reconstruction presented in this study can be used to estimate the effects of preindustrial land cover change, e.g., on hydrology, nutrient cycles, and regional to global climate. They can thereby contribute to a better understanding of the human role in past changes of the Earth system.

[55] A digital version of the millennium reconstruction of global agricultural areas and land cover is available from the World Data Center for Climate (doi:10.1594/WDCC/ RECON_LAND_COVER 800-1992). Please contact the authors for further information.

[56] Acknowledgments. The authors would like to thank Pavel Tarasov and Andreas Dix for their valuable suggestions on our reconstruction method. We are grateful to Navin Ramankutty for providing us with the SAGE 5 min and West Africa crop maps and his useful comments on them. We would like to thank Kees Klein Goldewijk for sharing his expert knowledge on historical agriculture and providing us with the HYDE 3.0 version, and Alberte Bondeau for her valuable suggestions on pasture data.

\section{References}

Allen, R. C. (2000), Economic structure and agricultural productivity in Europe, 1300-1800, in Eur. Rev. Econ. History, 3, 1-25.

Asner, G. P., A. J. Elmore, L. P. Olander, R. E. Martin, and A. T. Harris (2004), Grazing systems, ecosystem responses, and global change, Ann. Rev. Environ. Resour., 29, 261-299.

Barker, T., et al. (2007), Mitigation from a cross-sectoral perspective, in Climate Change 2007: Mitigation. Contribution of Working Group III to the Fourth Assessment Report of the Intergovernmental Panel on Climate Change, pp. 1-851, edited by B. Metz et al., Cambridge Univ. Press, Cambridge, UK.

Betts, R. A. (2001), Biogeophysical impacts of land use on present-day climate: Near-surface temperature change and radiative forcing, Atmos. Sci. Lett., 1, doi:10.1006/asle.2001.0023.

Biraben, J. N. (1979), Essai sur l'évolution du nombre des hommes, Population, 34(1), 13-25.

Boserup, E. (1965), The Conditions of Agricultural Growth, 124 pp., Aldine, Chicago, Ill.

Brovkin, V., A. Ganopolski, M. Claussen, C. Kubatzki, and V. Petoukhov (1999), Modelling climate response to historical land cover change, Global Ecol. Biogeogr., 8, 509-517.

Brown de Colstoun, E. C., R. S. DeFries, and J. R. G. Townshend (2006), Evaluation of ISLSCP Initiative II satellite-based land cover data sets and assessment of progress in land cover data for global modeling, J. Geophys. Res., 111, D22S07, doi:10.1029/2006JD007453.

Clark, C. (1967), Population Growth and Land Use, 2nd ed., 406 pp., Macmillan, London.

Crombie, A. C. (1977), Von Augustinus bis Galilei. Die Emanzipation der Naturwissenschaft, 637 pp., Dtsch. Tasch., Wiss. Reihe, München, Germany.

Davin, E. L., N. de Noblet-Ducoudré, and P. Friedlingstein (2007), Impact of land cover change on surface climate: Relevance of the radiative forcing concept, Geophys. Res. Lett., 34, L13702, doi:10.1029/ 2007GL029678.

DeFries, R. S., C. B. Field, I. Fung, G. J. Collatz, and L. Bounoua (1999), Combining satellite data and biogeochemical models to estimate global effects of human-induced land cover change on carbon emissions and primary productivity, Global Biogeochem. Cycles, 13(3), 803-815.

Denman, K. L., et al. (2007), Couplings between changes in the climate system and biogeochemistry, in Climate Change 2007: The Physical Science Basis. Contribution of Working Group I to the Fourth Assessment Report of the Intergovernmental Panel on Climate Change, edited by S. Solomon et al., pp. 499-587, Cambridge Univ. Press, Cambridge, UK.

Durand, J. D. (1977), Historical estimates of world population: An evaluation, Pop. Dev. Rev., 3(3), 253-296.

Foley, J. A. C. Delire, N. Ramankutty, and P. Snyder (2003), Green Surprise? How terrestrial ecosystems could affect Earth's climate, Frontiers Ecol. Environ., 1, 38-44.

Galloway, J. N., W. H. Schlesinger, H. Levy II, A. Michaels, and J. L. Schnoor (1995), Nitrogen fixation: Anthropogenic enhancement-environmental response, Global Biogeochem. Cycles, 9(2), 235-252.

Goosse, H., O. Arzel, J. Luterbacher, M. E. Mann, H. Renssen, N. Riedwyl, A. Timmermann, E. Xoplaki, and H. Wanner (2006), The origin of the European "Medieval Warm Period", Clim. Past, 2, 99-113.

Grigg, D. B. (1974), The Agricultural Systems of the World: An Evolutionary Approach, 358 pp., Cambridge Geogr. Stud., Cambridge Univ. Press, New York.

Haberl, H., K. H. Erb, F. Krausmann, V. Gaube, A. Bondeau, C. Plutzar, S. Gingrich, W. Lucht, and M. Fischer-Kowalski (2007), Quantifying and mapping the human appropriation of net primary production in Earth's terrestrial ecosystems, Proc. Natl. Acad. Sci., 104(31), 12,942-12,947.

Hanotte, O., D. G. Bradley, J. W. Ochieng, Y. Verjee, E. W. Hill, and J. E. O. Rege (2002), African pastoralism: Genetic imprints of origins and migrations, Science, 296(5566), 336-339.

Houghton, R. A. (1999), The annual net flux of carbon to the atmosphere from changes in land use 1850-1990, Tellus, Ser. B, 51, 298-313.

Houghton, R. A. (2003), Revised estimates of the annual net flux of carbon to the atmosphere from changes in land use $1850-2000$, Tellus, Ser. B, $55,378-390$

Houghton, R. A., and J. L. Hackler (1995), Continental scale estimates of the biotic carbon flux from land cover change: 1850-1980, technical report, 144 pp., Oak Ridge Natl. Lab., Oak Ridge, Tenn.

Houghton, R. A., J. E. Hobbie, J. M. Melillo, B. Moore, B. J. Peterson, G. R. Shaver, and G. M. Woodwell (1983), Changes in the carbon content of terrestrial biota and soils between 1860 and 1980: A net release of $\mathrm{CO}_{2}$ to the atmosphere, Ecol. Monogr., 53(3), 235-262.

Hurtt, G. C., S. Frolking, M. G. Fearon, B. Moore, E. Shevliakova, S. Malyshev, S. W. Pacala, and R. A. Houghton (2006), The underpinning of land-use history: Three centuries of global gridded land-use transitions, wood-harvest activity, and resulting secondary lands, Global Change Biol., $12,1208-1229$

Joos, F., S. Gerber, I. C. Prentice, B. L. Otto-Bliesner, and P. J. Valdes (2004), Transient simulations of Holocene atmospheric carbon dioxide and terrestrial carbon since the Last Glacial Maximum, Global Biogeochem. Cycles, 18, GB2002, doi:10.1029/2003GB002156.

Kerven, C., I. I. Alimaev, R. Behnke, G. Davidson, N. Malmakov, A. Smailov, and I. Wright (2006), Fragmenting pastoral mobility: Changing grazing patterns in post-Soviet Kazakhstan, USDA For. Serv. Proc., 39, 99-110.

Klein Goldewijk, K. (2001), Estimating global land use change over the past 300 years: The HYDE database, Global Biogeochem. Cycles, 15(2), 417-433.

Klein Goldewijk, K., and N. Ramankutty (2004), Land cover change over the last three centuries due to human activities: The availability of new global data sets, GeoJournal, 61, 335-344.

Maddison, A. (2001), The World Economy: A Millennial Perspective, 384 pp., Dev. Cent. of the Org. for Econ. Co-op. and Dev., Paris.

McEvedy, C., and R. Jones (1978), Atlas of World Population History, 368 pp., Penguin Books, Harmondsworth, UK.

Millennium Ecosystem Assessment (2005), Ecosystems and Human WellBeing: Synthesis, 155 pp., Island Press, Washington, D. C.

Pongratz, J., C. Reick, T. Raddatz, and M. Claussen (2008), A Global Land Cover Reconstruction AD 800 to 1992: Technical Description, Rep. on Earth Syst. Sci., vol. 51, 83 pp., Max Planck Inst. for Meteorol., Hamburg, Germany, ISSN 1614-1199.

Ramankutty, N. (2004), Croplands in West Africa: A geographically explicit dataset for use in models, Earth Interact., 8(23), 1-22.

Ramankutty, N. (2006), Global land-cover change: Recent progress, remaining challenges, in Land-Use and Land-Cover Change. Local processes and Global Impacts, edited by E. F. Lambin and H. J. Geist, IGBP Ser., pp. 9-39, Springer, Berlin.

Ramankutty, N., and J. A. Foley (1998), Characterizing patterns of global land use: An analysis of global croplands data, Global Biogeochem Cycles, 12(4), 667-685. 
Ramankutty, N., and J. A. Foley (1999), Estimating historical changes in global land cover: Croplands from 1700 to 1992, Global Biogeochem. Cycles, 13(4), 997-1027.

Richards, J. F. (1990), Transformations of the global environment: Land transformation, in The Earth as Transformed by Human Action: Global and Regional Changes in the Biosphere Over the Past 300 Years, edited by B. L. Turner, pp. 163-178, Cambridge Univ. Press, New York.

Ruddiman, W. (2007), Early anthropogenic hypothesis: Challenges and responses, Rev. Geophys., 45, RG4001, doi:10.1029/2006RG000207.

Ruttan, V. (2002), Productivity growth in world agriculture: Sources and constraints, J. Econ. Perspect., 16(4), 161-184.

Sieferle, R. P. (1997), Rückblick auf die Natur, 236 pp., Luchterhand, München.

Slicher van Bath, B. H. (1963), Yield Ratios, 810-1820, 264 pp., Landbouwhogheschool, Afdeling Agarische Geschiedenis, Wageningen, Germany.

Stendel, M., I. A. Mogensen, and J. H. Christensen (2006), Influence of various forcings on global climate in historical times using a coupled atmosphere-ocean general circulation model, Clim. Dyn., 26, 1-15.
Tett, S. F. B., R. Betts, T. J. Crowley, J. Gregory, T. C. Johns, A. Jones, T. J. Osborn, E. Öström, D. L. Roberts, and M. J. Woodage (2007), The impact of natural and anthropogenic forcings on climate and hydrology since 1550, Clim. Dyn., 28, 3-34.

Townshend, J., C. Justice, W. Li, C. Gurney, and J. McManus (1991), Global land cover classification by remote sensing: Present capabilities and future possibilities, Remote Sens. Environ., 35(2-3), 243-255.

United Nations Environment Program (UNEP) (1995), Global Biodiversity Assessment, 1140 pp., Cambridge Univ. Press, Cambridge, UK

Vasey, D. E. (1992), An Ecological History of Agriculture: 10,000 B. C. -A. D. 10,000, 363 pp., Iowa State Univ. Press, Ames, Ia

Vitousek, P. M., H. A. Mooney, J. Lubchenco, and J. M. Melillo (1997) Human domination of Earth's ecosystems, Science, 277(5325), 494-499.

M. Claussen, J. Pongratz, T. Raddatz, and C. Reick, Max Planck Institute for Meteorology, Bundesstrasse 53, D-20146 Hamburg, Germany. (martin. claussen@zmaw.de; julia.pongratz@zmaw.de; thomas.raddatz@zmaw.de; christian.reick@zmaw.de) 